\title{
CYP2C19 genotype variability in patients with refractory gastroesophageal reflux after per-oral endoscopic myotomy (POEM)
}

\section{다(1) $(5)$}

\author{
Authors \\ Institutions \\ 1 Department of Internal Medicine, University of Florida, \\ Gainesville, Florida, United States \\ 2 Division of Gastroenterology and Hepatology, University \\ of Florida, Gainesville, Florida, United States
}

Yaseen B. Perbtani ${ }^{1}$, Donevan R. Westerveld ${ }^{2}$, Dennis J. Yang ${ }^{1}$, Peter V. Draganov ${ }^{1}$

submitted 10.10 .2020

accepted after revision 15.2 .2021

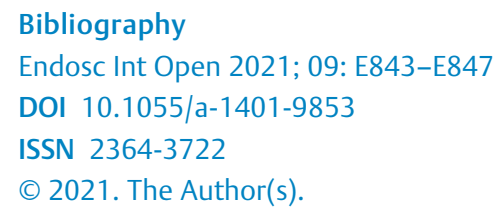
Commons Attribution-NonDerivative-NonCommercial License, permitting copying and reproduction so long as the original work is given appropriate credit. Contents may not be used for commercial purposes, or adapted, remixed, transformed or built upon. (https://creativecommons.org/licenses/by-nc-nd/4.0/)

Georg Thieme Verlag KG, Rüdigerstraße 14,

70469 Stuttgart, Germany

Corresponding author

Peter V. Draganov, MD, Division of Gastroenterology, University of Florida, 1329 SW 16th Street, Suite 5251, Gainesville, FL 32608, United States

Fax: +1-352-627-9002

Peter.Draganov@medicine.ufl.edu

\section{ABSTRACT}

Background and study aims Symptomatic gastroesophageal reflux is a recognized potential adverse event following peroral endoscopic myotomy (POEM). Proton pump inhibitors (PPIs) are an effective first-line therapy; although their efficacy can be affected by genotype cytochrome P450 2C19 (CYP2C19) variability leading to enhanced clearance of PPIs. The aim of our study was to evaluate the incidence of CYP2C19 genotype variability in POEM patients with refractory gastroesophageal reflux symptoms.

Patients and methods This was a single-center, prospective, cohort study of consecutive POEM cases during a 7year study period (2013-2020). Reflux symptoms were assessed with the validated gastroesophageal reflux disease questionnaire (GerdQ) and objective $\mathrm{pH}$ testing after POEM. CYP2C19 genotype testing was obtained in all patients with refractory gastroesophageal reflux disease (GERD) symptoms, defined as an abnormal pH study and GerdQ score $\geq 8$ while on PPIs twice daily.

Results POEM was performed in 325 consecutive patients ( $48.3 \%$ female; mean age 57 years) during the study period. Twenty patients (6.8\%) had PPI-refractory, post-POEM gastroesophageal reflux based on their GerdQ score (median 9, range $8-11$ ) and abnormal pH studies. CYP2C19 genotype testing identified $55 \%(11 / 20)$ of these patients as being rapid metabolizers. Out of these, 9 (82\%) had improvement in clinical GERD symptoms after changing to a PPI less affected by CYP2C19 pharmacogenetics.

Conclusions Post-POEM, PPI-refractory GERD is rare. As shown in this study, rapid metabolizers commonly respond by changing to a PPI less affected by CYP2C19 pharmacogenetics, thereby reducing the risk of long-term consequences from GERD and unnecessary anti-reflux surgery.

\section{Introduction}

Per-oral endoscopic myotomy (POEM), initially introduced in clinical practice in 2008 [1], has become the mainstay of therapy for achalasia and esophageal spastic disorders. Post-POEM gastroesophageal reflux disease (GERD) is a well-recognized entity that can have direct impact on quality of life (QOL), lead to esophagitis, peptic stricture and Barrett's esophagus [2]. While proton pump inhibitors (PPIs) are an effective first-line therapy in most patients [3], a subset of individuals may have ongoing symptoms and/or objective evidence of uncontrolled reflux on endoscopy or $\mathrm{pH}$ testing in spite of maximum medical therapy. There are multiple potential reasons for PPI failure, including noncompliance, inappropriate dosing or timing of PPI 
administration, large volume non-acidic reflux, and esophageal hypersensitivity to physiologic reflux [4]. From a pharmacogenetic standpoint, PPI-induced acid suppression is closely related to their enzymatic clearance in the liver by cytochrome P450 2C19 (CYP2C19). Hence, variations in CYP2C19 activity have been shown to modulate medication efficacy [5]. Indeed, CYP2C19 genetic variability is the most important and well-recognized pharmacogenetic factor affecting response to PPIs [6]. Increases in function polymorphisms in CYP2C19 alleles may be associated with enhanced clearance of PPIs, which can lead to suboptimal intragastric $\mathrm{pH}$ and diminished control of GERD-like symptoms [7]. Prevalence of increased function polymorphisms is relatively common, occurring in up to $35 \%$ in patients with either African or European ancestry [6]. Still, the incidence and significance of CYP2C19 variability in postPOEM patients with poorly controlled GERD symptoms have not been well characterized. Herein, the aim of our study was to evaluate the prevalence of CYP2C19 genotype variability in patients with refractory GERD symptoms after POEM.

\section{Patients and methods}

This was a single-center prospective cohort study that was approved by the Institutional Review Board at the University of Florida (trial number: NCT01832779). The study period was from March 2013 to February 2020. The POEM procedure was performed as previously described [1]. A descriptive summary of collected data was compiled for analysis using either mean and standard deviation or median and interquartile range (IQR).

Patients were classified according to the Chicago Classification of esophageal motility disorders [8]. Data collection included demographics, type of esophageal motility disorder, duration of symptoms, procedural parameters, Eckardt score and gastroesophageal reflux symptoms based on the validated GERD questionnaire (GerdQ) [9] (\Supplemental Table 1). Clinical success was determined by a post-POEM Eckardt score $\leq 3$.

Following POEM, all patients were routinely placed on PPI daily until their initial clinic follow-up scheduled at 1 to 3 months post-procedure. PPI was discontinued in asymptomatic patients whereas continued at the twice daily dose in those with persistent GERD symptoms. All patients were subsequently scheduled to undergo objective testing with $\mathrm{pH}$ impedance study (performed while off PPI) at their 6-month follow-up.
Patients with refractory post-POEM GERD, defined by GerdQ score $\geq 8$ while on PPI twice daily and abnormal pH study, underwent endoscopy and testing for polymorphisms in CYP2C19.

The phenotypic status of CYP2C19 was classified according to the Clinical Pharmacogenomics Consortium Guidelines [10], and classified into three categories ( $\triangleright$ Table 1 ): Normal metabolizers were homozygous for wild type allele CYP2C19*1; intermediate low metabolizers were heterozygous for genotype CYP2C19*2 and rapid metabolizers were homozygous for CYP2C19*17 or heterozygous with wild type allele $\left({ }^{*} 1 /{ }^{*} 17\right)$.

\section{Results}

POEM was successfully performed in 325 consecutive patients (48.3\% female; mean age 57 years) during the study period. A total of 293 of 325 patients had at least 1 month clinical follow up. Clinical success (Eckardt score $\leq 3$ ) was achieved in $97 \%$ of the cases (284/293).

Of the 293 patients, 170 (58\%) remained on either once- or twice-daily PPIs at a median follow-up of 6 months (IQR 1-14) after their procedure. Their overall mean GerdQ score was $7.8 \pm$ 2.6. Post-POEM pH testing was obtained in 125 of these patients, of which 88 (70\%) had an abnormal total acid exposure time greater than $4 \%$.

Twenty patients (20/293; 6.8\%), on PPI twice daily, had refractory post-POEM GERD symptoms, based on their GerdQ scores $>8$ (median 9, range 8-11) and abnormal pH study. Patient and procedural characteristics for this cohort are summarized in Table2. Endoscopy, which was performed in 17 of these 20 patients, demonstrated erosive esophagitis in $58.8 \%$ (10/17). CYP2C19 genotype testing in all 20 patients identified 11 (55\%) rapid metabolizers, six (30\%) intermediate low metabolizers, and three (15\%) normal metabolizers. Most of these patients $(13 / 20 ; 65 \%)$ achieved adequate control of their GERD symptoms either by increasing the total daily dosage of their current PPI or by changing to another PPI less affected by CYP2C19 pharmacokinetics (i.e. rabeprazole or esomeprazole) ( $\triangleright$ Table 3). Seven patients (2 CYP2C19 rapid metabolizers and 5 intermediate or normal metabolizers) underwent laparoscopic fundoplication for symptomatic management. Of these, four patients reported improvement after their surgery ( $\triangleright$ Table 3).

- Table 1 Assignment of CYP2C19 phenotype based on genotype.

\begin{tabular}{|c|c|c|}
\hline & CYP2C19 phenotype & CYP2C19 genotype \\
\hline Reduced CYP2C19 activity & $\begin{array}{l}\text { Intermediate/poor metabolizer } \\
\text { Expected to respond well to standard dose of a PPI }\end{array}$ & ${ }^{*} 1 /{ }^{*} 2,{ }^{*} 2 /^{*} 17,\left.{ }^{*} 4\right|^{*} 17$ \\
\hline Typical CYP2C19 activity & $\begin{array}{l}\text { Normal metabolizer } \\
\text { Expected to respond to a standard dose of a PPI }\end{array}$ & ${ }^{*} 1 /{ }^{*} 1$ \\
\hline Increased CYP2C19 activity & $\begin{array}{l}\text { Rapid Metabolizer } \\
\text { Less likely to respond to a standard dose of a PPI }\end{array}$ & "17/*17, " $1 /{ }^{*} 17$ \\
\hline
\end{tabular}


- Table 2 Procedural and demographic characteristics of patients with refractory post-POEM GERD symptoms in spite of being on PPI twice daily $(n=20)$.

\begin{tabular}{|c|c|c|}
\hline & Pre-POEM & Post-POEM \\
\hline Age, mean \pm SD & $54.9 \pm 15.4$ & \\
\hline \multicolumn{2}{|l|}{ Sex; n (\%) } & \\
\hline - Male & $6(30)$ & \\
\hline - Female & $14(70)$ & \\
\hline \multicolumn{2}{|l|}{ Type of esophageal motility disorder, n (\%) } & \\
\hline - Type 1 & $2(10)$ & \\
\hline - Type 2 & $11(55)$ & \\
\hline - Type 3 & $2(10)$ & \\
\hline - Jackhammer esophagus & $4(20)$ & \\
\hline $\begin{array}{l}\text { - Esophagogastric outlet obstruc- } \\
\text { tion }\end{array}$ & $1(5)$ & \\
\hline Abnormal GerdQ score $\geq 8, \mathrm{n}(\%)$ & $10(50)$ & \\
\hline \multicolumn{2}{|l|}{ POEM myotomy length $(\mathrm{cm})$, mean \pm SD } & \\
\hline - Esophageal & $11.1 \pm 1.6$ & \\
\hline - Gastric & $3 \pm 1.9$ & \\
\hline - Total & $13.9 \pm 1.7$ & \\
\hline $\begin{array}{l}\text { Abnormal time } \mathrm{pH}<4 \text { on } 24 \text {-hour } \mathrm{pH} \\
\text { monitoring, } \mathrm{n} / \mathrm{N}(\%)\end{array}$ & & $18 / 20(90)$ \\
\hline $\begin{array}{l}\text { Total (\%) lower esophageal acid expo- } \\
\text { sure time, mean } \pm \text { SD }\end{array}$ & & $32.4 \pm 15.4$ \\
\hline $\begin{array}{l}\text { Abnormal total reflux episodes, } \mathrm{n} / \mathrm{N} \\
(\%)\end{array}$ & & $8 / 20(40)$ \\
\hline $\begin{array}{l}\text { Positive reflux-symptom association, } \\
\mathrm{n} / \mathrm{N}\end{array}$ & & 0 \\
\hline Evidence of esophagitis, n/N (\%) & & $10 / 17(58.9)$ \\
\hline
\end{tabular}

\section{Discussion}

PPI is the first-line treatment for patients with post-POEM GERd. In this study, we demonstrate that PPI refractory postPOEM GERD was uncommon (6.8\%). Importantly, more than half of these patients were identified to carry the CYP2C19 rapid metabolizer genotype.

PPIs are metabolized by the liver enzyme CYP2C19. It is well known that the pharmacokinetics and pharmacodynamics of PPIs differ based on CYP2C19 genotypes. In this study, we demonstrated that the more than half of the patients with PPI refractory post-POEM GERD were CYP2C19 rapid metabolizers. Our data is consistent with prior studies identifying CYP2C19 rapid metabolizer genotype as a risk factor for being refractory to PPI therapy [11]. Indeed, in a recent meta-analysis of 15 studies, Ichikawa et al. demonstrated that rapid metabolizers were associated with a higher risk of being refractory to PPI therapy (odds ratio 1.66; $95 \%$ confidence interval: 1.02-2.66;
$P=0.04$ ) among patients with known reflux esophagitis [12]. Hence, establishing CYP2C19 genotype in patients on PPI therapy, particularly in those with refractory symptoms, can trigger meaningful clinical decisions. In this study, we demonstrated that most CYP2C19 rapid metabolizers with refractory post POEM GERD symptoms responded by switching them to a PPI less influenced by CYP2C19 polymorphisms (i. e. esomeprazole or rabeprazole) [6]. This is an example of how personalizing PPI regimens based on CYP2C19 genotype can be considered as a potential strategy before considering surgical referral for antireflux therapy.

Our study is not without limitations. CYP2C19 genotype testing was not obtained in all patients prior to POEM, therefore negating the true prevalence of CYP2C19 genotype variability. Nevertheless, this is the first series to report frequency of CYP2C19 genotype variability in patients with refractory GERD symptoms following POEM; thereby providing evidence supporting the role of CYP2C19 status-tailored PPI therapy. Second, we recognize that the resolution of gastroesophageal reflux symptoms following CYP2C19 genotype testing and treatment was heavily reliant on symptom scores. While the GerdQ scoring system is a validated assessment tool used to assess the presence of GERD, it may lack sensitivity when used as a standalone measure. As previously reported by Jones et al. [13], GERD symptoms correlate poorly with objective $\mathrm{pH}$ testing after POEM - further highlighting that subjective symptoms alone may be inadequate when evaluating for post-POEM GERD. Furthermore, we acknowledge that uncontrolled acid reflux is only part of the spectrum of etiologies in post-POEM patients with GERD symptoms. Other potential causes, including regurgitation in the setting of persistent esophageal dysmotility and acidification of luminal contents due to esophageal stasis were not investigated in this study.

\section{Conclusions}

In summary, our results suggest that post-POEM PPI-refractory GERD is relatively rare and frequently related to CYP2C19 genotype variability affecting PPI pharmacokinetics. Importantly, patients who were identified to be CYP2C19-genotype rapid metabolizers were successfully managed by changing to a PPI less affected by the CYP2C19 pathway, potentially preventing long-term consequences from GERD and avoidance of antireflux surgery. Our findings support the need for further prospective studies and raises the important question about the need for CYP2C19 genotype testing prior to POEM in all patients as it may affect the management strategy prior to intervention.

\section{Competing interests}

The authors declare that they have no conflict of interest. 
- Table 3 Patient and clinical outcomes following CYP2C19 testing.

\begin{tabular}{|c|c|c|c|c|}
\hline Patient & CYP2C19 genotype & CYP2C19 predicted phenotype & Medical therapy & Outcome \\
\hline 1 & $* 1 /{ }^{*} 17$ & Rapid & Rabeprazole $20 \mathrm{mg}$, TID & Improvement of clinical symptoms \\
\hline 2 & * $1 /{ }^{*} 17$ & Rapid & Rabeprazole $20 \mathrm{mg}$, TID & Improvement of clinical symptoms \\
\hline 3 & $* 1 /{ }^{*} 17$ & Rapid & Rabeprazole $20 \mathrm{mg}$, TID & Improvement of clinical symptoms \\
\hline 4 & $* 1 /{ }^{*} 17$ & Rapid & Rabeprazole $20 \mathrm{mg}$, TID & Improvement of clinical symptoms \\
\hline 5 & $* 1 /{ }^{*} 17$ & Rapid & Rabeprazole $20 \mathrm{mg}$, TID & Improvement of clinical symptoms \\
\hline 6 & $* 1 /{ }^{*} 17$ & Rapid & Rabeprazole $20 \mathrm{mg}$, TID & Improvement of clinical symptoms \\
\hline 7 & ${ }^{*} 1 /{ }^{*} 17$ & Rapid & Rabeprazole $20 \mathrm{mg}$, QID & Pending Follow-up \\
\hline 8 & $* 1 /{ }^{*} 17$ & Rapid & Dexlansoprazole, $60 \mathrm{mg}$ BID & Persistent symptoms, fundoplication \\
\hline 9 & $\left.{ }^{*} 17\right|^{*} 17$ & Rapid & Esomeprazole, $80 \mathrm{mg}$ TID & Improvement of clinical symptoms \\
\hline 10 & ${ }^{*} 17 /{ }^{*} 17$ & Rapid & Rabeprazole $20 \mathrm{mg}$, TID & Improvement of clinical symptoms \\
\hline 11 & $\left.{ }^{*} 17\right|^{*} 17$ & Rapid & Pantoprazole, $80 \mathrm{mg}$ TID & Persistent symptoms, fundoplication \\
\hline 12 & $* 2 / 17$ & Intermediate & Dexlansoprazole, $60 \mathrm{mg}$ & Improvement of clinical symptoms \\
\hline 13 & $* 2 / 17$ & Intermediate & Dexlansoprazole, $60 \mathrm{mg}$ & Improvement of clinical symptoms \\
\hline 14 & $* 2 /{ }^{*} 17$ & Intermediate & Esomeprazole 40 mg BID & Persistent symptoms, fundoplication \\
\hline 15 & $4 /^{*} 17^{*}$ & Intermediate & Rabeprazole 20 mg TID & Pending Follow-up \\
\hline 16 & $4 / /^{*} 17^{*}$ & Intermediate & Pantoprazole $80 \mathrm{mg}$ TID & Pending Follow-up \\
\hline 17 & ${ }^{*} 1 /{ }^{*} 2$ & Intermediate & Pantoprazole, $40 \mathrm{mg}$ BID & Persistent symptoms, fundoplication \\
\hline 18 & $*{ }^{*} 1$ & Normal & Pantoprazole, $40 \mathrm{mg}$ BID & Persistent symptoms, fundoplication \\
\hline 19 & ${ }^{*} 1 /{ }^{*} 1$ & Normal & Pantoprazole, $40 \mathrm{mg}$ BID & Persistent symptoms, fundoplication \\
\hline 20 & ${ }^{*} 1 /{ }^{*} 1$ & Normal & Pantoprazole, $40 \mathrm{mg}$ BID & Persistent symptoms, fundoplication \\
\hline
\end{tabular}

\section{References}

[1] Inoue $\mathrm{H}$, Minami $\mathrm{H}$, Kobayashi $\mathrm{Y}$ et al. Peroral endoscopic myotomy (POEM) for esophageal achalasia. Endoscopy 2010; 42: 265-271

[2] Inoue H, Shiwaku H, Kobayashi $Y$ et al. Statement for gastroesophageal reflux disease after peroral endoscopic myotomy from an international multicenter experience. Esophagus 2020; 17: 3-10

[3] Repici A, Fuccio L, Maselli R et al. GERD after per-oral endoscopic myotomy as compared with Heller's myotomy with fundoplication: a systematic review with meta-analysis. Gastrointest Endosc 2018; 87: 934-943.e918

[4] Subramanian CR, Triadafilopoulos G. Refractory gastroesophageal reflux disease. Gastroenterol Rep 2015; 3: 41-53

[5] Andersson T, Holmberg J, Röhss K et al. Pharmacokinetics and effect on caffeine metabolism of the proton pump inhibitors, omeprazole, lansoprazole, and pantoprazole. Br J Clin Pharmacol 1998; 45: 369375

[6] El Rouby N, Lima JJ, Johnson JA. Proton pump inhibitors: from CYP2C19 pharmacogenetics to precision medicine. Expert Opin Drug Metab Toxicol 2018; 14: 447-460

[7] Furuta T, Sugimoto M, Kodaira C et al. CYP2C19 genotype is associated with symptomatic recurrence of GERD during maintenance therapy with low-dose lansoprazole. Eur J Clin Pharmacol 2009; 65: 693-698
[8] Kahrilas PJ, Bredenoord AJ, Fox M et al. The Chicago Classification of esophageal motility disorders, v3.0. Neurogastroenterol Motil 2015; 27: $160-174$

[9] Jones R, Junghard O, Dent J et al. Development of the GerdQ, a tool for the diagnosis and management of gastro-oesophageal reflux disease in primary care. Aliment Pharmacol Ther 2009; 30: 1030-1038

[10] Scott SA, Sangkuhl K, Gardner EE et al. Clinical Pharmacogenetics Implementation Consortium guidelines for cytochrome P450-2C19 (CYP2C19) genotype and clopidogrel therapy. Clin Pharmacol Ther 2011; 90: 328-332

[11] Furuta T, Shirai N, Watanabe F et al. Effect of cytochrome P4502C19 genotypic differences on cure rates for gastroesophageal reflux disease by lansoprazole. Clin Pharmacol Ther 2002; 72: 453-460

[12] Ichikawa H, Sugimoto M, Sugimoto K et al. Rapid metabolizer genotype of CYP2C19 is a risk factor of being refractory to proton pump inhibitor therapy for reflux esophagitis. J Gastroenterol Hepatol 2016: 31: 716-726

[13] Jones EL, Meara MP, Schwartz JS et al. Gastroesophageal reflux symptoms do not correlate with objective $\mathrm{pH}$ testing after peroral endoscopic myotomy. Surg Endosc 2016; 30: 947-952 
- Supplemental Table 1 GerdQ questionnaire [9].

\begin{tabular}{|c|c|c|c|c|}
\hline Question & 0 day & 1 day & 2-3 days & 4-7 days \\
\hline How often did you have a burning feeling behind your breastbone (heartburn)? & 0 & 1 & 2 & 3 \\
\hline $\begin{array}{l}\text { How often did you have stomach contents (liquid or food) moving upwards to your throat or mouth } \\
\text { (regurgitation)? }\end{array}$ & 0 & 1 & 2 & 3 \\
\hline How often did you have a pain in the centre of the upper stomach? & 3 & 2 & 1 & 0 \\
\hline How often did you have nausea? & 3 & 2 & 1 & 0 \\
\hline $\begin{array}{l}\text { How often did you have difficulty getting a good night's sleep because of your heartburn and/or } \\
\text { regurgitation? }\end{array}$ & 0 & 1 & 2 & 3 \\
\hline $\begin{array}{l}\text { How often did you take additional medication for your heartburn and/or regurgitation, other than } \\
\text { what the physician told you to take? (such as Tums, Rolaids, Maalox?) }\end{array}$ & 0 & 1 & 2 & 3 \\
\hline
\end{tabular}

